\section{Leiomyoma on Nasal Dorsum}

Hwan Jun Choi ${ }^{1}$, Kyu Hwa Jung ${ }^{1}$, Jee Hye Lee ${ }^{2}$

Departments of Plastic and Reconstrucive Surgery and ${ }^{2}$ Pathology, Soonchunhyang Cheonan University Hospital, Soonchunhyang University College of Medicine, Cheonan, Korea

\section{Correspondence: Hwan Jun Choi}

Department of Plastic and Reconstructive Surgery Soonchunhyang Cheonan University Hospital, Soonchunhyang University College of Medicine, 31 Suncheonhyang 6-gil, Dongnam-gu, Cheonan 330-721, Korea Tel: +82-41-570-2195, Fax: +82-41-570-6133

E-mail:medi619@hanmail.net

This work was supported by the Soonchunhyang University Research Fund.

No potential conflict of interest relevant to this article was reported

Received: 25 Mar 2014 • Revised: 2 May 2014 • Accepted: 4 May 2014 pISSN: 2234-6163・ elSSN: 2234-6171

http://dx.doi.org/10.5999/aps.2015.42.1.98 • Arch Plast Surg 2015;42:98-100

Copyright (C) 2015 The Korean Society of Plastic and Reconstructive Surgeons This is an Open Access article distributed under the terms of the Creative Commons

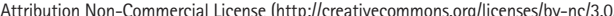
medium, provided the original work is properly cited.

Leiomyomas are benign tumor of smooth muscle origin, most commonly found in the uterus and gastrointestinal tract [1]. Less than 1\% happen in some head and neck structure [2]. Especially, they are rare in nose because of paucity of smooth muscle. Almost those cases are usually confined to the subcutaneous tissue and skin, rarely occurring in the deep tissue. We report a 10-year-old female with leiomyoma of the nasal dorsum arising from the deep tissue.

A 10-year-old female was referred to our hospital with a slowly increase in the size of mass for the last 4 years. She has no history of trauma in the years just before the tumor was recognized. Physical examination showed a oval shaped $1.5 \times 1 \mathrm{~cm}$ mass

Fig. 1.

Preoperative photographic finding shows a $1.5 \times 1 \mathrm{~cm}$ sized oval shaped mass on the right nasal lateral wall in a 10-year-old girl. on the right nasal side wall, which was non movable and tenderness to palpation (Fig. 1). Contrast enhanced computed tomography revealed an ovalshaped nodule that was located in the right nasal dorsum subcutaneous fat layer, most suspected dermoid cyst. It was very close to the nasal bone, but there was no bony erosion and destruction (Fig. 2).

The mass was excised using a direct incision under general anesthesia. In operation, the mass are adhered to the skin, fascia and small vessels. The mass including attached skin was separated from the underlying nasalis muscle. We biopsied the lesion and the pathology report classified it as a leiomyoma with degeneration change in central area, confirmed based on the immunohistochemistry showing desmin negativity and smooth muscle actin positivity (Fig. $3)$. After the resection of the lesion, the patient underwent an observation of 3 months' follow-up, and no recurrence was detected (Fig. 4).

Soft tissue leiomyomas can be subdivided into three distinct groups. The most common form, the cutaneous leiomyoma, arises from the erector pili muscles of the skin and the deep dermis of the scrotum, labia major, and nipple [3]. The second group of soft tissue leiomyomas, the angioleiomyomas (also known as angiomyomas or vascular leiomyomas), are differentiated by their subcutaneous location and histology, which is characterized by a conglomeration of thick-walled vessels associated with smooth muscle tissue. These are solitary lesions and most commonly present in the adult, with two thirds occurring in the fourth through sixth decades. These lesions are typically small $(<2 \mathrm{~cm})$ and located

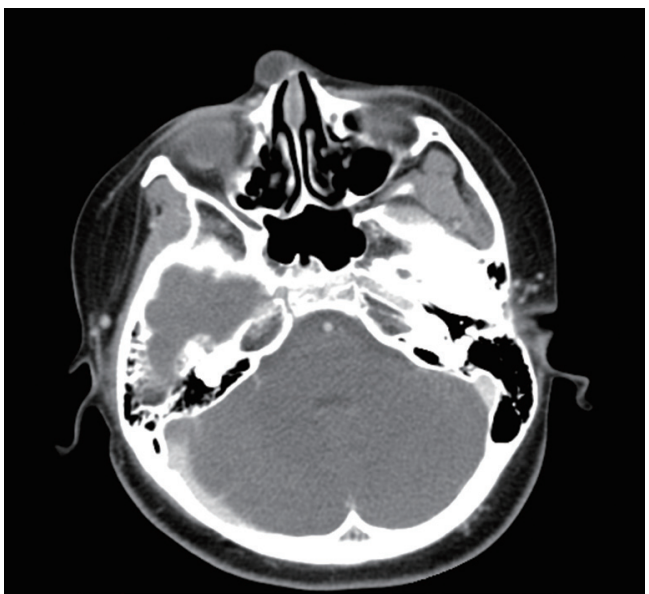

Fig. 2.

Axial enhanced computed tomography scan shows an oval-shaped nodule that was located in the right nasal dorsum subcutaneous fat layer, close to the nasal bone. 

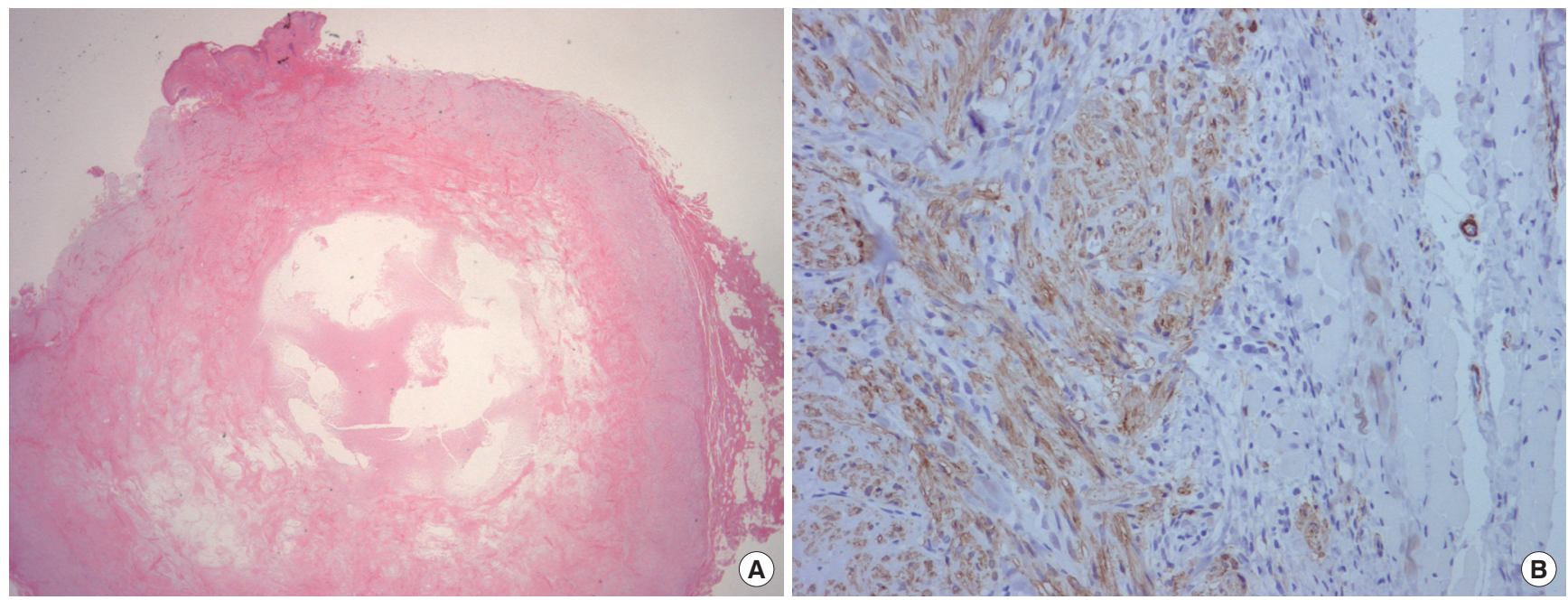

Fig. 3.

(A) Microscopic findings shows bundles of smooth muscle cells with collagen fibers with degeneration change in central area $\left(H \& E_{1} \times 40\right)$.

(B) Immunohistochemical finding shows positivity for smooth muscle actin $(\times 200)$.

in the extremities [3]. The third group, leiomyomas of the deep soft tissues, may be located in the deep soft tissues of the extremities or the retroperitoneum. The retroperitoneal variety is more commonly found in females, possibly reflecting an origin from hormonally sensitive smooth muscle. Deeper lesions are usually larger, probably because of a delay in detection, and frequently present carried histological alterations, more likely to be confused with leiomyosarcoma [3].

Prior to our report, some cases were reported, but almost nasal cavity and paranasal sinus, in the second group. In our case, younger patient has an isolated, nodular soft tissue mass in the external nose that was large enough to approaching the nasal bone imaged with CT. It was a nonvascular leiomyoma originating from deep tissue, with degeneration change.

Among the soft tissue tumors in the head and neck area, $96 \%$ area known to be benign, and leiomyomas comprise only $1.3 \%$ of them [4]. Although there are no malignant degeneration report, the presence of benign areas of leiomyoma within leiomyosarcoma specimens raises such a possibility [1]. Recently, immunohistochemistries with mitosis-specific reagent phosphohistone- $\mathrm{H} 3$ and $\mathrm{Ki}-67$ were even reported because of the differentiated surgical plan [5]. Therefore, leiomyoma must be differentiated from neurofibroma, angiofibroma, schwannoma, myofibroma, leiomyosarcoma, and surgical excision with postoperative histopathologic analysis should be considered.

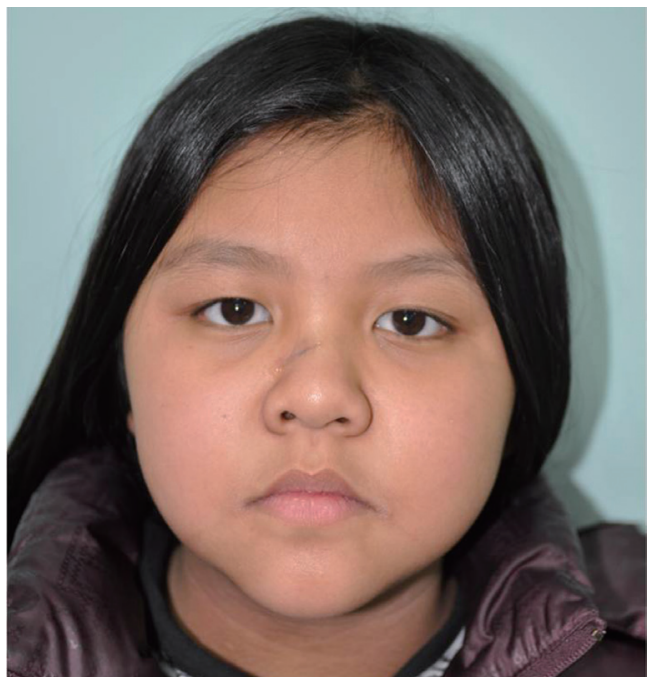

Fig. 4.

Postoperative 3 months photographic finding reveals removal of the nasal lateral wall mass, no recurrence was detected.

\section{References}

1. Cizmeci O, Tuncer S, Tuzlali S. Leiomyoma of the nasal dorsum and excision with open rhinoplasty approach. J Plast Reconstr Aesthet Surg 2007;60:689-90.

2. Campelo VE, Neves MC, Nakanishi M, et al. Nasal cavity vascular leiomyoma: case report and literature review. Braz J Otorhinolaryngol 2008;74:147-50.

3. Enzinger FM, Weiss SW. Benign tumors of smooth muscle. In: Weiss SW, Goldblum JR, editors. Soft tissue tumors. 4th ed. St. Louis: CV Mosby; 1995. p.695-6.

4. Kwon JH, Lim SY, Lim HS. Leiomyoma of the forehead. 
Arch Plast Surg 2013;40:165-7.

5. Idriss MH, Kazlouskaya V, Malhotra S, et al.

Phosphohistone-H3 and Ki-67 immunostaining in

cutaneous pilar leiomyoma and leiomyosarcoma

(atypical intradermal smooth muscle neoplasm).J

Cutan Pathol 2013;40:557-63.

\section{The Rare Presentation of Extraskeletal Ewing's Sarcoma on the Forehead}

Sung Hoon $\mathrm{Choi}^{1}$, Young Joon $\mathrm{Kim}^{1}$, Hoon $\mathrm{Kim}^{1}$, Hyun-Jung Kim², Sang Hyun Nam ${ }^{1}$,

Young Woong Choi ${ }^{1}$

Departments of ${ }^{1}$ Plastic and Reconstructive Surgery and ${ }^{2}$ Pathology, Sanggye Paik Hospital, Inje University College of Medicine, Seoul, Korea

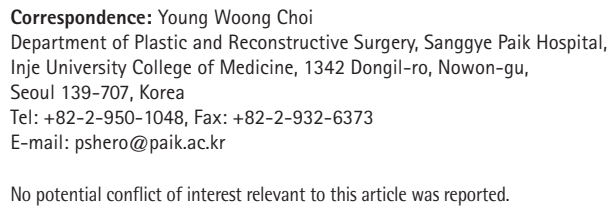

No potential conflict of interest relevant to this article was reported.

Received: 6 Mar 2014 • Revised: 24 Mar 2014• Accepted: 27 Mar 2014 pISSN: 2234-6163・ elSSN: 2234-6171

http://dx.doi.org/10.5999/aps.2015.42.1.100 • Arch Plast Surg 2015;42:100-102

Copyright (C) 2015 The Korean Society of Plastic and Reconstructive Surgeons

This is an Open Access article distributed under the terms of the Creative Commons

Attribution Non-Commercial License (http://creativecommons.org/licenses/by-nc/3.0/) which permits unrestricted non-commercial use, distribution, and reproduction in any medium, provided the original work is properly cited.

Fig. 1.

Preoperative photograph showing a non-tender mobile soft tissue (black arrow) mass on the forehead.
Extraskeletal Ewing's sarcoma (EES) is a rare round cell malignant neoplasm with rapid growth and an uncharacterized mesenchymal cell origin, and it is histologically similar to Ewing's sarcoma (ES) arising from bone [1]. EES was first described as a paravertebral 'round cell' tumor morphologically resembling ES of bone by in 1969 [1,2]. In 1975, a review of 39 patients was reported about malignant soft tissue tumors not arising from bone but with histomorphologic characteristics similar to primary osseous ES [1,2].

The sites of involvement varied, yet there appeared to be a tendency to involve the paravertebral region, intercostal area, lower extremities and pelvis [1]. EES rarely occurs in the head and neck region, with only five cases reported in a series of 118 patients in the four largest series in the English literature $[1,3]$. Furthermore, another report indicated that only 5\% to $11 \%$ of EES cases occur in the head and neck region, and the nose, eyelid, nasopharynx, parotid gland, scalp, and parapharyngeal space have been described $[3,4]$.

However, we encountered EES on the forehead. To the best of our knowledge, there have been no reports regarding EES originating from the forehead. Two years ago, a 35-year-old male patient presented with a palpable and non-tender mass. The mass size was $2 \times 2 \mathrm{~cm}$, and there were no other problems. Excision was performed in a local clinic one year ago. After excision, he had no clinical symptoms. However, 3 months ago, a $1 \times 1 \mathrm{~cm}$ mobile, protruding mass recurred on the patient's forehead (Figs. 1, 2). The patient visited our department for further evaluation and treatment. At the initial physical examination, lymph node enlargement in the neck, weight loss, tenderness and other clinical problems were not observed.

Radiologic evaluation demonstrated no invasion or any destruction of the frontal bone. X-ray examination showed a soft tissue mass with muscle tissue invasion that was without calcification or onion skin-like radiation characteristics, which are specific to osseous ES (Fig. 3).

Under local anesthesia, excisional biopsy was performed. An approximately $1.0 \times 1.0 \mathrm{~cm}$ tissue mass was excised. The pathologic report revealed monomorphic proliferation of small, blue, round cell tumors with scanty cytoplasm and the absence of rosette-like structures (Fig. 4). Immunohistochemical staining demonstrated that the tumor cells were positive for vimentin, CD99, CD56, and neuron- 